\title{
Shrinking core model of demineralization of chitin isolation from shrimp shell
}

\author{
Ahmad Fadli ${ }^{1, *}$, Subkhan Maulana ${ }^{1}$, and Drastinawati ${ }^{1}$ \\ ${ }^{1}$ Department of Chemical Engineering, Universitas Riau, Pekanbaru, Indonesia
}

\begin{abstract}
Chitin is a naturally abundant polymer and most of it was used as a surfactant and cosmetic raw materials. Chitin be able to derive from natural sources like shrimp shell waste. The aim of this research was to study the kinetic model of chitin demineralization with approach to shrinking core model (SCM) with variation of hydrochloric acid concentration. There models were used: Fluid Film Layer Diffusion, Ash Layer Diffusion and Chemical Reaction. It was began with deproteination at first with $\mathrm{NaOH} 3,5 \%$ and continued with demineralization using hydrochloric acid at concentration $0,3 \mathrm{~N} ; 0,6 \mathrm{~N} ; 0,9 \mathrm{~N}$ and $1,2 \mathrm{~N}$ with variation of reaction time at 15, 30 and 15 minute. The calcium content in the product was analyzed after it was dried in the air oven. The results showed calcium concentration decrease along with increasing of hydrochloric acid concentration. It get kinetic model at concentration $0,3 \mathrm{~N}$ of hydrochloric acid usage with form:
\end{abstract}

$$
1-\left(\frac{r_{c}}{R}\right)^{3}=X_{B}
$$

with the highest value of $\mathrm{R}^{2}$ is 0,9555 and the smallest percentage error is $5,92 \%$. Meanwhile with usage of hydrochloric acid at concentration $0,6 \mathrm{~N} ; 0,9 \mathrm{~N}$ and $1,2 \mathrm{~N}$ were get kinetic model with form:

$$
\frac{t}{\tau}=1-3\left(1-X_{B}\right)^{2 / 3}+2\left(1-X_{B}\right)
$$

with the highest value of $R^{2}$ is 0,9794 .

\section{Introduction}

Potential source of fishery industry such as shrimp shell waste has been limited to feed and a lot of it has caused environmental problem. Utilization of waste for added value features two strategic approaches; both provide benefit to the producers and solve environmental problems by carrying out the principle of "Zero Waste Products" [10]. Chitin is abundant compound in nature estimated annual production reaches $10^{10}-10^{12}$ tons [8]. Chitin content in shrimp shell waste is about $20-50 \%$ dry weight [4]. Chitin properties are stable against chemical reactions, non-toxic and biodegradable. As the second most abundant biopolymer in the world, chitin can be found mainly in invertebrates, insects, marine diatoms, algae, fungi, and yeasts. Chitin has widely used such as mobilization of enzymes, metal adsorbents, films and fibers, anti-radar material and anti-cancer drugs. Conventionally, chitin was isolated from crustacean shells by deproteination in alkaline solution and followed by demineralization in acid solution [2]. One source of chitin is shrimp shell waste. Shrimp shell waste can be obtained from shrimp processing industry in Indragiri Hilir regency with the amount of waste about 1-3 tons/month. The main raw material of dried shrimp processing business is red shrimp (Metapenaeus Sp).
Demineralization is the process of removing minerals contained in a material by the addition of a low concentration of hydrochloric acid solution. This process aims to eliminate minerals contained in shrimp shell [3]. Shrimp shell generally contains 20$50 \%$ of minerals depending on the species [7]. Calcium carbonate $\left(\mathrm{CaCO}_{3}\right)$ is the main composition of minerals contained in shrimp shells, wherein the calcium concentration be able to determine by the complexometric method [5]. Calcium content reduction occurring in shrimp waste particle can be described using a heterogeneous kinetic model with the shrinking core model approach [9]. Wherein, the film layer and ash layer were hydrochloric acid and protein respectively. The utilization of shrimp shell waste into chitin, chitosan and its derivative products is highly potential for wider applications and improves its added value [8]. The wide range of chitin applications makes it useful to be studied for both isolation and kinetic data. Chitin isolation requires an appropriate reactor to produce high quality chitin. Reactor design also required kinetics data at any concentration, temperature and reaction time for better control and optimization of the process. Based on the description above, kinetic data which can be 
obtained should be used to design and optimize the demineralization reactor to get good quality chitin.

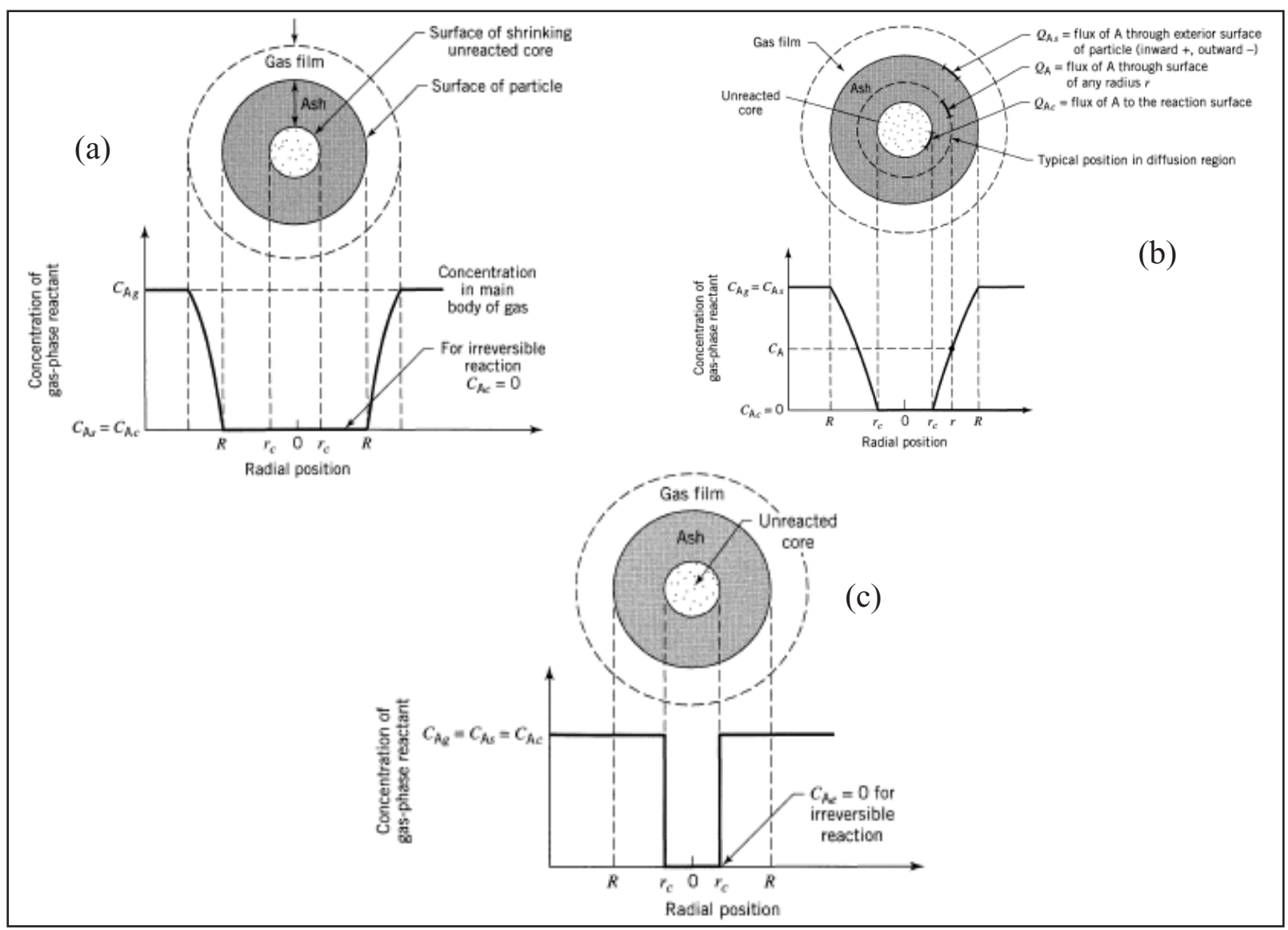

Fig. 1. (a) Fluid Film Controls (Model 1) (b) Ash Layer Diffusion Controls (Model 2) (c) Chemical Reaction Controls (Model 3) [6].

\section{Materials and Methods}

The shrimp shell waste was obtained from local dried shrimp industry in Riau, Indonesia. The exoskeleton of the shrimp was manually washed, dried, and sieved at 20 dan 35 mesh. Hydrochloric acid pro analysis (pa) product grade from Merck was procured and prepared into four concentrations $(0.3,0.6,0.9$, and $1.2 \mathrm{~N})$. Materials for analysis using complexometric titration such as solid EDTA, EBT indicator, buffer $\mathrm{pH} 10, \mathrm{HNO}_{3}$ and $\mathrm{H}_{2} \mathrm{SO}_{4}$ were purchased and 0,01 M EDTA solution was prepared by dissolving $3.7724 \mathrm{~g}$ EDTA $\left(\mathrm{Na}_{2} \mathrm{H}_{2} \mathrm{Y} .{ }_{2} \mathrm{H}_{2} \mathrm{O}\right)$ in $50 \mathrm{ml}$ deionized water with constant stirring for $15 \mathrm{~min}$ in a 250 $\mathrm{ml}$ volumetric flask. When the solid crystals of EDTA were completely dissolved, the volume was made up to the mark.

\section{Experimentation}

\subsection{Deproteination}

$100 \mathrm{~g}$ of shrimp shell was soaked and stirred in 3.5\% solution of $\mathrm{NaOH}$ in the mass to volume ratio of $1: 10$ for $240 \mathrm{~min}$ by boiling at $65^{\circ} \mathrm{C}$ for deproteination process. After a given time interval, the content of the conical flask was quickly filtered using filter paper. The solid residue then washed severally with distilled water, until neutrality and its alkalinity determined by the $\mathrm{pH}$-indicator paper and a $\mathrm{pH}$ meter (Kent EIL 7055). The deproteinized samples were dried and weighed and referred to as demineralized sample for 0 minute.

\subsection{Demineralization}

Various concentrations of hydrochloric acid solution $(0.3,0.6,0.9$, and $1.2 \mathrm{~N})$ were prepared by dissolving hydrochloric acid in distilled water. The prepared shrimp shells placed in a $250 \mathrm{ml}$ conical flask and quickly mixed with $0.3 \mathrm{M}$ hydrochloric acid solution in the mass to volume ratio of 1:10. The content of the conical flask was maintained for 15 minutes, with stirring using a magnetic stirrer. After a given time interval, the content of the conical flask was quickly injected with syringe and filtered using a filter paper. The solid residue then washed severally with distilled water, until neutrality and its acidity determined by $\mathrm{pH}$-indicator paper and a $\mathrm{pH}$ meter (Kent EIL 7055). The demineralized samples were dried and weighed. 


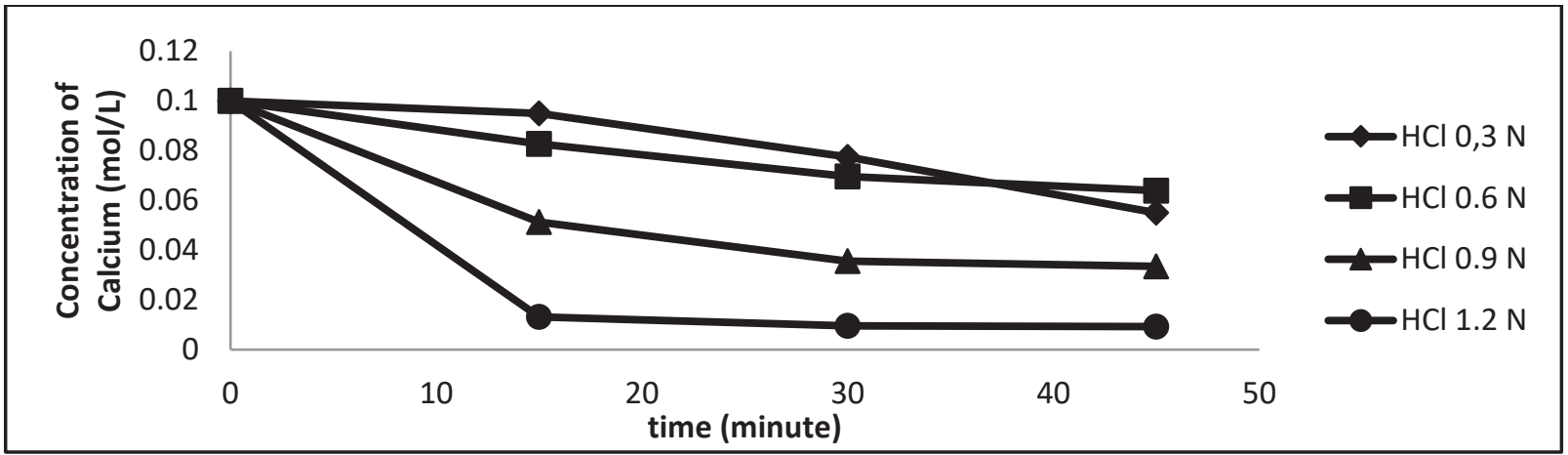

Fig. 2. Reduction of calcium content of demineralized shrimp shell due to hydrochloric acid treatment

These steps were then repeated in turns for other reaction times of 30 and 45 minutes. The entire procedure was then repeated for the other hydrochloric acid concentrations of $0.6,0.9$ and $1.2 \mathrm{~N}$.

\subsection{Analysis}

For the determination of calcium content, $0.5 \mathrm{~g}$ of sample was mixed into $5 \mathrm{~mL}$ of sulfuric acid and $5 \mathrm{~mL}$ of nitric acid. In the pipette a $1 \mathrm{~mL}$ aliquot of the sample solution into a conical flask with added $100 \mathrm{~mL}$ of distilled water. In the pipette a $1 \mathrm{~mL}$ aliquot of the sample solution into another conical flask and add $0.1 \mathrm{~g}$ of EBT indicator with $1 \mathrm{ml}$ of buffer solution ( $\mathrm{pH}-10)$ and swirl the solution to dissolve the indicator. The chitin solution was titrated with the EDTA solution. The endpoint is a color change from pink/red to blue.

\section{Kinetics modeling}

The shrinking core model (SCM) was considered as it models fluid-particle reactions [20]. The models for the various SCM control mechanism are:

1. For fluid-film diffusion control (FFDC)

$$
\frac{t}{\tau}=X_{B}
$$

2. For ash layer diffusion control (ALDC)

$$
\frac{t}{\tau}=1-3\left(1-X_{B}\right)^{2 / 3}+2\left(1-X_{B}\right)=M_{2}
$$

3. For chemical reaction control (CRC)

$$
\frac{t}{\tau}=1-\left(1-X_{B}\right)^{\frac{1}{3}}=M_{3}
$$

Where $\tau$ : time for complete reaction, $\mathrm{X}_{\mathrm{B}}$ : conversion of calcium The right hand side of equation 1,2 and 3 were plotted against $t$ and the fit $R^{2}$ were computed.

\section{Result and Discussion}

Figure 1 presents the progression in the concentration of calcium in the demineralized shrimp shells with time for the various acid concentrations considered. Figure 2 indicates a progressive drop in the concentration of the calcium for all hydrochloric acid concentrations along with time. Reduction of calcium content and increment of conversion or amount of calcium removed directly proportional due to increasing of hydrochloric acid concentration. For instance, after 45 minutes of demineralization the conversion of calcium for $0.3 \mathrm{~N}$ and $1.2 \mathrm{~N}$ hydrochloric acid solutions were $45 \%$ and $90,74 \%$ respectively. Figures 3-6 below present the fitting of the kinetic data to the shrinking core model.

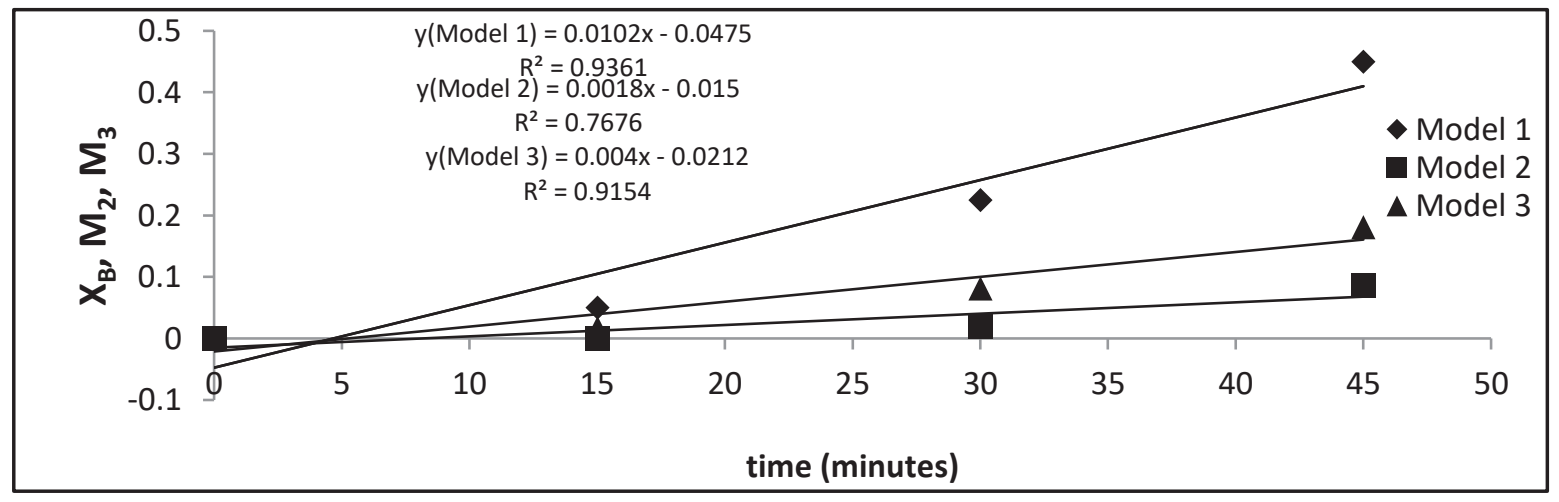

Fig. 3. SCM for shrimp shell demineralization using $0.3 \mathrm{~N}$ hydrochloric acid solution 


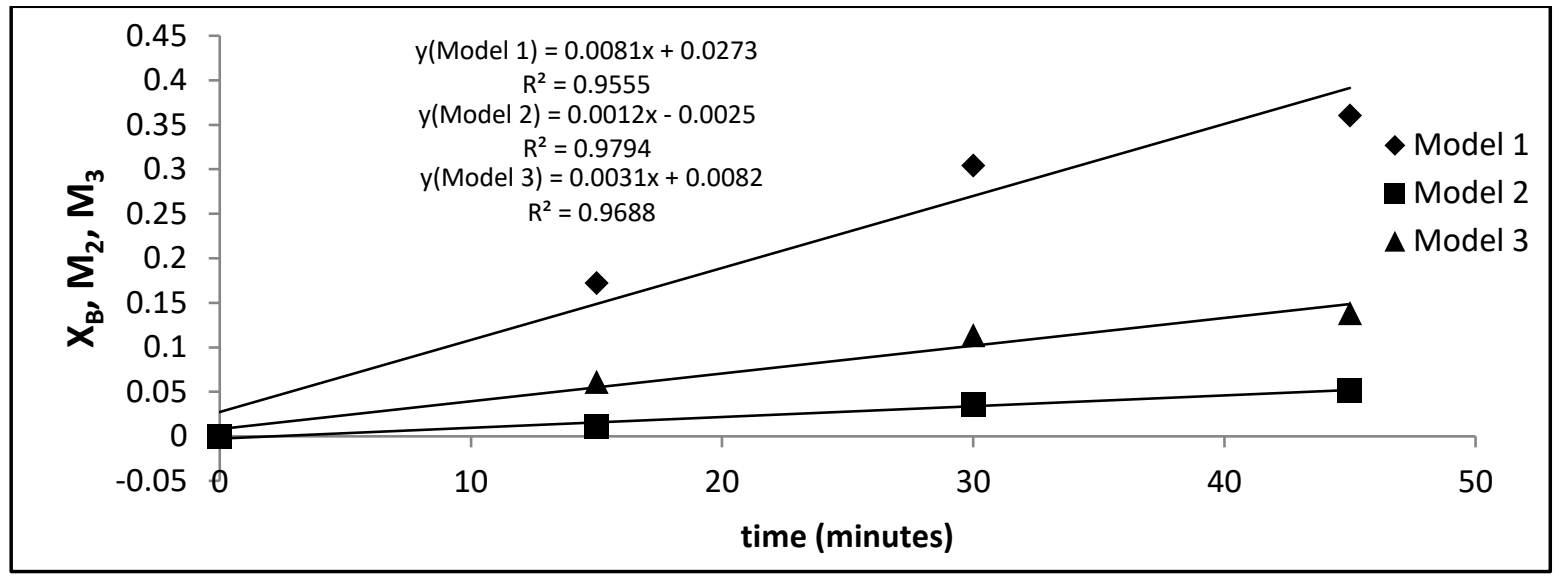

Fig. 4. SCM for shrimp shell demineralization using $0.6 \mathrm{~N}$ hydrochloric acid solution

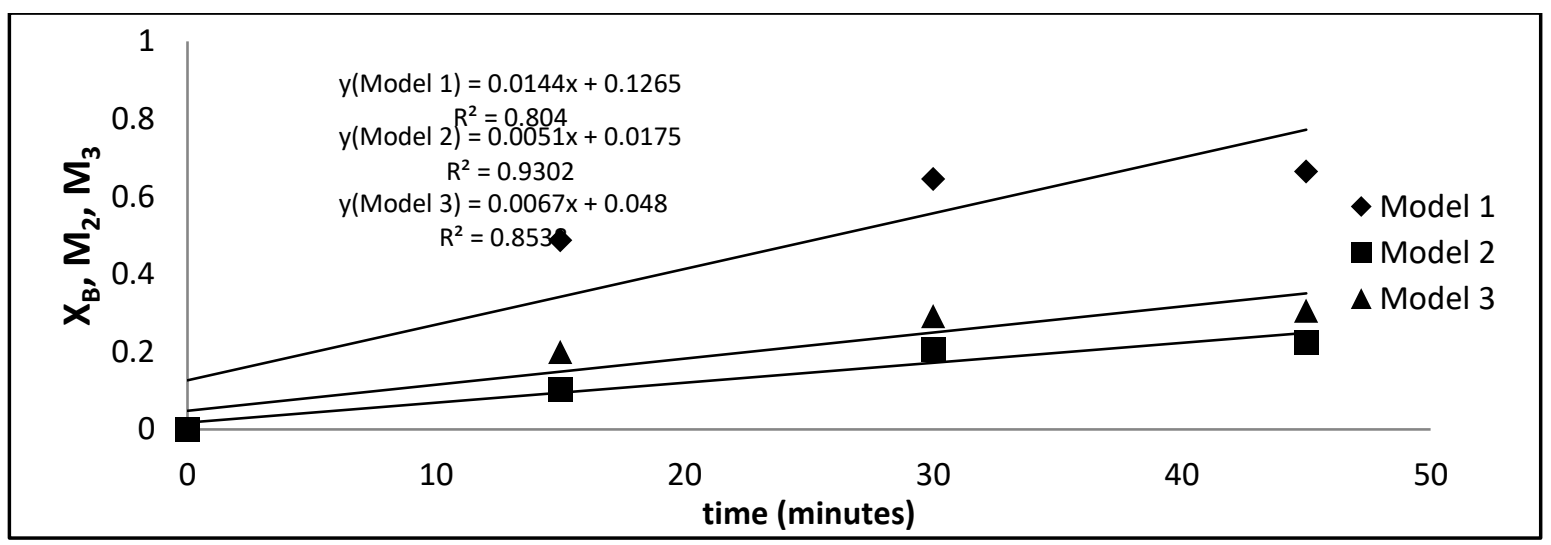

Fig. 5. SCM for shrimp shell demineralization using $0.9 \mathrm{M}$ hydrochloric acid solution

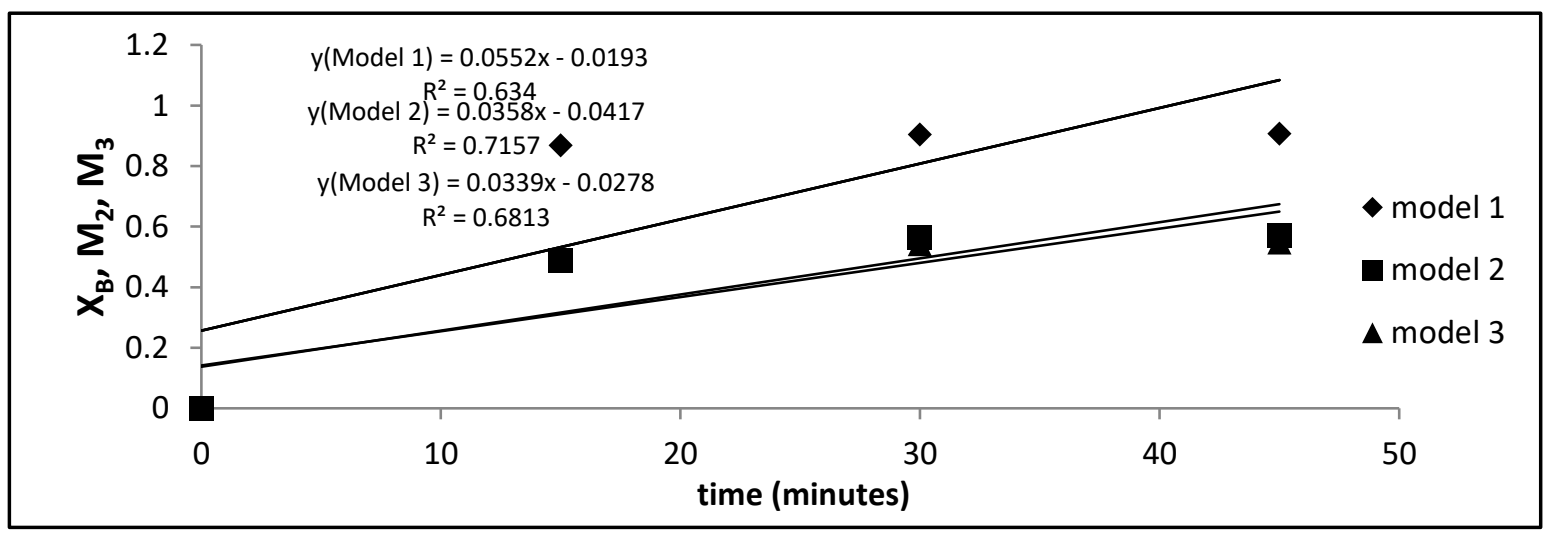

Fig. 6. SCM for shrimp demineralization using $1.2 \mathrm{~N}$ hydrochloric acid solution 
Figures 3-6 denoted all of kinetics modeling equations $\mathrm{X}_{\mathrm{B}}, \mathrm{M}_{2}, \mathrm{M}_{3}$ are plot against time to find out the highest determination coefficient $\left(\mathrm{R}^{2}\right)$ value. Figures 3 showed that the fluid film diffusion control (model 1) gave a better approximation of the demineralization process compared to ash layer diffusion control mechanism (model 2) and chemical reaction control (model 3). The highest coefficient determination $\left(\mathrm{R}^{2}\right)$ value is fluid film diffusion model (model 1). This kinetic model occurs when the reactant has a sufficient driving force to diffuse in the film layer. Liquid films in shrimp shell particles was formed when the Reynold number (Re) $>1000$ [7] which Re in this experiment is 1524 . The laminar boundary layer enveloping the particles made low concentration reactant such as hydrochloric acid $0.3 \mathrm{~N}$ still in diffuse stages through the film layer to the shrimp shell particle. Figures 4-6 showed that the ash layer diffusion control mechanism (model 2) gave a better approximation of the demineralization process compared to fluid film diffusion control (model 2) or chemical reaction control (model 3). The relative magnitudes of the $\mathrm{R}^{2}$ values are indicative of this: for hydrochloric acid at $0.3 \mathrm{~N}, 0.9 \mathrm{~N}$ and $1.2 \mathrm{~N}$ considered, the highest of $\mathrm{R}^{2}$ values were for ash layer diffusion model. There is a difference of results between demineralization using hydrochloric acid concentration of $0.3 \mathrm{~N}$ and $0.6 \mathrm{~N}, 0.9 \mathrm{~N}, 1.2 \mathrm{~N}$.

Demineralization using hydrochloric acid $0.3 \mathrm{~N}$ gave a better approximation of kinetic model of film diffusion controls (model 1). Demineralization reaction using $0.6 \mathrm{~N}$ $\mathrm{HCl} ; 0.9 \mathrm{~N}$ and $1,2 \mathrm{~N}$ showed that the ash layer diffusion (model 2) gave a better approximation compared to the fluid film diffusion (model 1) and chemical reaction controls (model 3).

This is due to the increasing of acid concentration as well as driving force on this reaction so that the diffusion can take place more optimal. One of the most important factor of the kinetic model is the concentration of reactant that affect the intensity of diffusion. Due to increasing of concentration of reactant then it brings hydrochloric acid with greater driving force become easier to diffuse through the film layer and follow by diffuse through the ash layer.

For ash layer diffusion model (model 2) reaction it is visualized that a wall of ash (nonreactive materials) prevents the fluid from moving freely to the zone of reaction (unreacted core). Demineralization of shrimp shells made the other unreactive materials such as protein and chitin should be a resistance. The results of this investigation are widely different from that was reported by Ameh et al. [1] which it was reported that the chemical reaction controls (model 3) gave the best prediction. Ameh et al. [1] also reported the XRF machine being unfamiliar with biological materials (matrix). This result showed that calcium content analysis with complexometric has widely difference result against Ameh et al. [1] which was used XRF for analysis. On the other hand it was showed that SCM give a better step and approximation according to increment of acid concentration.

\section{Conclusion}

Shrimp shell was demineralized using hydrochloric acid at concentration $0.3 \mathrm{~N}, 0.6 \mathrm{~N}, 0.9 \mathrm{~N}$, and $1.2 \mathrm{~N}$. The concentration of hydrochloric acid affected the conversion of calcium and its kinetic modeling. Analysis of the kinetic data using shrinking core model denoted different results. Demineralization used hydrochloric acid at concentration $0.3 \mathrm{~N}$ got film diffusion control (model 1) and at concentration $0.6 \mathrm{~N}, 0.9 \mathrm{~N}, 1.2 \mathrm{~N}$ indicated ash layer diffusion control (model 2) as the best approximation.

\section{References}

1. Ameh, A.O., M.T. Isa, T.J. Adeleye, K.K. Adama, Kinetics of demineralization of shrimp exoskeleton in chitin and chitosan synthesis, Leonardo Electronic Journal of Practices and Technologies. 4(3) pp. 32-37 (2013)

2. Ameh A.O., D. Abutu, M. T. Isa, U. Rabiu, Kinetics of demineralization of shrimp shell using lactic acid, Leonardo Electronic Journal of Practices and Technologies. 24 pp. 13-22 (2014)

3. Ameh A.O., M.T. Isa, D. Abutu, A. Danlami, Kinetic modelling of the demineralization of shrimp exoskeleton using citric acid, Leonardo Electronic Journal of Practices and Technologies. 25 pp. 99-108 (2014)

4. Horton, R.H., Moran, L.A., Ochs, R.S., Rawn. J.D. and Scrimgeour, K.G, Principles of Biochemistry, Third edition, Prentice-Hall, Inc., (New York, 2002)

5. Hussain, Z., A. Nazir, U. Shafique, M. Salman, Comparative study for the determination of metals in milk samples using flame-AAS and EDTA Complexometric Titration, Journal of Scientific Research 40 pp. 9-14 (2010)

6. Levenspiel, O, Chemical Reaction Engineering, $3^{\text {nd }}$ ed, John Willey and Sons Inc., (Singapore, 1999)

7. Munson, B., D.F. Young, T.H. Okiishi, Fluid Mechanic, $4^{\text {th }}$ ed, Erlangga., (Jakarta, 2004)

8. Ravichandran, S., G. Rameshkumardan A.R. Prince, Biochemical Composition of Shell and Flesh of the Indian White Shrimp Penaeus Indicus (H.Milne Edwards 1837), Journal of Scientific Research., 4(3) pp. 191-194 (2009)

9. Roberts, G.A.F. Chitin Chemistry, $1^{\text {st }}$ ed, MacMillan., (London 1992)

10. Wibowo, S, Research on utilization of shrimp fishery waste for chitosan production and its application to support food industry, Applied Research Incentive Program, Research and Development Agency of Marine and Fisheries., (Jakarta, 2008) 